\title{
Synchronous distance learning and virtual classrooms: A case study on student expectations and conditioning factors
}

\author{
Darío M. Goussal and María Sandra Udrízar Lezcano \\ Universidad Nacional del Nordeste-Resistencia, Argentina
}

\begin{abstract}
In order to cope with increasing enrolment demands and funding constraints, some multi-campus universities in developing regions have considered distance learning (DL) as a way to facilitate access, while improving course delivery effectiveness. This paper presents a survey on students' perceptions about hypothetical implementations of DL systems, in particular the use of synchronous two way transmission and virtual classrooms in new locations. We explored three main areas of interest: firstly student profiles, and their cost and time constraints under the traditional system; secondly, pre-adoption perceptions about various DL options; and thirdly, differences in perceived impacts for individuals enrolled in different subjects. Data gathered sequentially from two subsamples in non-consecutive years (1999 and 2001) enabled numerous crosssection and longitudinal operations. We present examples of findings on the cost-benefit ratios, relative priorities and pre-adoption factors affecting decisions on both institutional and pedagogical issues.
\end{abstract}

\section{Background}

The literature about evaluation of distance learning technologies in universities typically includes case studies, implementation and methodological aspects, as in the works by Stubbs \& Burnham (1990), Moore \& Benbasat (1991), Renner (1995), Marney-Petix (1996), Walters \& Reed (1997), Trushell et at (1997), Burnham \& Walden (1997), Shakeshaft (1999), Mann (1999), Redding (2000) and Johnstone (2000), among other authors. Most of them report outcome and comparison findings of already accomplished projects, in order to provide the necessary data to fuel institutional self assessment, customisation, cross-checking and feedback. By contrast, pre-adoption studies (Lane, 1989) are quite scarce, mostly comprising small scale surveys, not necessarily focused on distance learning and universities, but rather on technology usage and technology acceptance behaviour. 
In developing regions, there is little chance for educational institutions to embark upon costly experimental projects without reasonable background and indications on their relative effectiveness and timeliness. Too many constraints and restricted budgets inhibit public universities from trying educational technologies, when available, with normal experimentation periods and accepted success / failure margins. Due to large intra-regional disparities in infrastructure, resources and application context, a higher degree of customisation in every long run initiative is regarded as mandatory in developing regions. As a result, the most appropriate choices in planning and implementation strategies may differ substantially between regions in the same country. A success story developed in one region or context may prove to be inapplicable in another. There is a greater need for more focused, deeper pre-adoption studies, particularly on university students' reactions, learning environment and technology adoption behavior. For example, one recent medium sized study concerning technology adoption by undergraduates, though within a postadoption approach, is Selim's (2003) survey of 403 students to investigate the acceptance of course websites, drawing upon the Technology Acceptance Model developed by Davis (1986, 1989, 1993).

We report here upon a large pre-adoption perception survey, conducted in two stages (1999 and 2001) in 3 regional campuses of UNNE (Universidad Nacional del Nordeste, Argentina) to assess the long term feasibility of a prospective synchronous distance learning system. UNNE is a public federal university, with 16 schools and institutes scattered in two neighboring provinces, Chaco and Corrientes, in the north-eastern littoral of Argentina (Figure 1). With about 53,000 students at the time of the study, UNNE enrols about $5 \%$ of the total numbers at Argentina's federal universities. The campuses in Resistencia (population 360,000 in 2001), Roque Saenz Peña (population 88,000), both in the province of Chaco and $170 \mathrm{~km}$ apart each other, and Corrientes (population 322,000), the capital of another province just $25 \mathrm{~km}$ away from Resistencia, are UNNE's main facilities for traditional delivery, with in person, face to face live classes. Because of the distribution of the disciplines taught at existing campuses in each city, and due to the number of non-residents spread out elsewhere in the region, a high proportion of students and professors must commute several times each week to attend their courses, resulting in a waste of time and resources and likely impacting on graduation and dropout rates. The DL application context is, to some extent, similar to that of the Tokyo Technological Institute's twin campuses at Okayama and Nagatsuda (Murakami, 1983), the University of California at Santa Cruz (MarneyPetix, 1996), and representative of daily commuting patterns revealed from other twin city learning communities in Argentina, for example, La Plata and Buenos Aires; Rosario, Santa Fe and Paraná; Salta and Jujuy; and in other regional, multi-campus universities worldwide. 


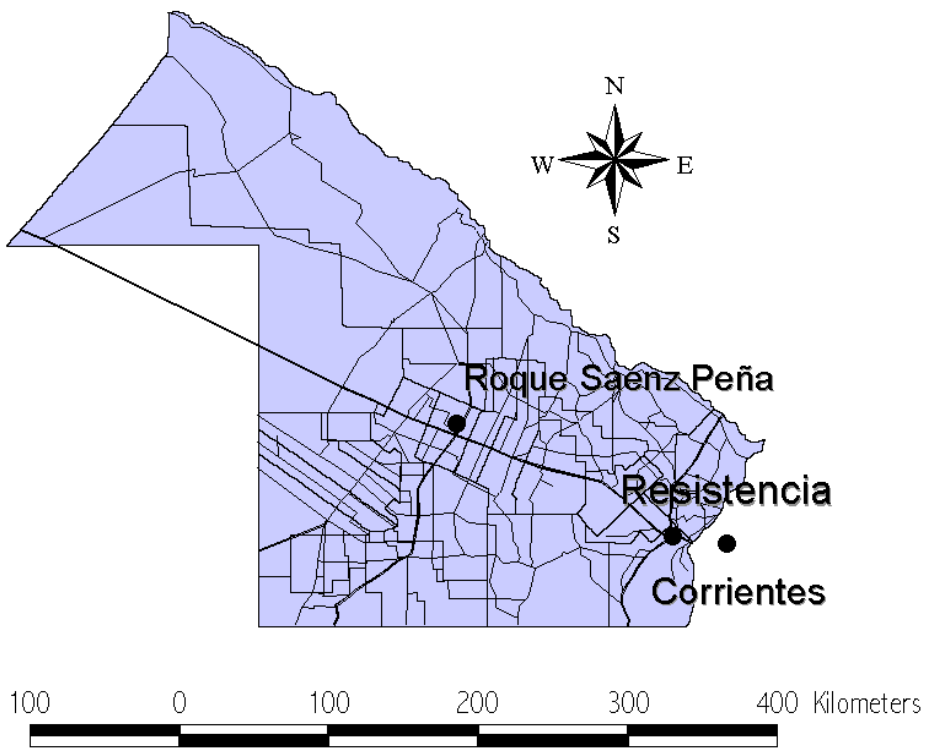

Figure 1: UNNE campus locations in the proposed implementation area

In 1995/1996, in view of high growth in annual enrolments, and as a part of the studies of the proposed ROCHA/ROU Project (Chaco Optical Route/University Optical Route), consideration was given to the use of medium-haul IP/CWDM inter-campus optical backbone links to convey live classroom video, voice and data sessions between existing UNNE campuses in Resistencia, Roque Saenz Peña and Corrientes, and potential new "virtual" campuses in other locations. Broadband transmission systems became an option for investigation, on the basis of reducing travel and housing costs and time wasted by thousands of individuals commuting daily to participate in lectures held in different cities 30 to 300 $\mathrm{km}$ apart each other. However the concept of "live virtual classrooms", inspired by early experiences with fibre optics in Japanese universities in the 1980s requires extensive feasibility studies on the learning, institutional and economic aspects, along with the examination of the implementation difficulties that are typical in developing regions (Renner, 1995).

\section{Survey design and methodology}

Perceived effectiveness of distance learning has been more extensively used in post-implementation assessments, thereby benefiting from the references that individuals have about their recent exposure to technology (O’Malley, 1999; Marney-Petix, 1996; Trushell et al, 1997). However, it is 
possible to measure respondents' perceptions in a pre-adoption study, provided that the lack of references from a tangible experience will imply a more complicated survey design and a less direct interpretation of responses. As the instruments to some extent require respondents to consider hypothetical situations, it is realised that personal judgments about some items will be necessarily of a contingent nature (Lane, 1989).

Considering these limitations, the survey instruments were designed by using alternating Delphi and brainstorming sessions, consultation and successive feedback adjustments via small pilot surveys. Then at each of the targeted campuses we performed harvest operations, random in time, course level and unit, consisting of a brief presentation and explanation on the nature of the study, delivery and immediate collection of completed survey forms during live, regular lectures in "flash" sessions averaging some 20 minutes. The operations, covering groups of anonymous respondents, gathered perceptions on the prospective application of DL technologies at UNNE from faculty, undergraduates and graduate students attending classes in 48 scientific disciplines. The target size of the inquiry was 3,000 respondents, with the student sample producing 2,629 valid forms. It was conducted in two stages covering the campuses of Resistencia, Roque Saenz Peña and Corrientes.

We adopted a panel analysis approach using data gathered in two nonconsecutive years (1999, with 1,268 participating students and 2001, gathering 1,361 responses). Because the two set of responses were extracted randomly from different schools and institutes, it was assumed to contain a small degree of mutual overlapping. In order to enable information self checking and screening, a series of t-tests and comparisons were computed between both collections, thereby ensuring their statistical reliability and consistency. We assumed that individuals had little or no prior exposure to synchronous learning systems, since no such systems were ever available in the region. Thus, the instrument was tuned to assess application context and pre-adoption expectations, rather than effects resulting from an already accomplished learning experience.

The instrument for the student survey contained three sections with a total of 22 questions in Spanish, 15 multiple choice and 7 open requests. The first section was descriptive for career, campus and current course enrolment; city of origin, temporary and permanent residence addresses, class schedule, employment status, work and class schedule overlaps; monthly expenditures in accommodation and commuting, and time spent in commuting to attend live class sessions.

The second part explored the learning environment and conditioning or driving factors, such as computer skills and related English language skills 
(to a large extent, academic activities and courses at UNNE are conducted in Spanish), off campus PC and Internet access, and a subjective assessment of the current distribution, location and schedule for classes.

The last section aimed to reveal student expectations and preferences about distance learning alternatives, including synchronous or asynchronous technologies, individual or collective delivery, suggested time allocation between live classes and DL virtual classes; subjective judgements on the most appropriate subjects to be taught via virtual classroom sessions within the study field and career pursued; and finally, a self assessment of personal degrees of motivation and concentration, in the event of having to study DL technology based courses. The 1999 and the 2001 sub-samples covered different career fields and schools, but the instrument retained the same format and implementation procedures.

The returned responses were repeatedly filtered by cross-screening based on matrix analysis of questions of the control set. Responses labeled as incoherent or incomplete were discarded and 2,629 valid responses were accepted as reliable (1,268 from the 1999 sub-sample and 1,361 from 2001). In order to further check statistical reliability and consistency, we held a common set of schools and institutes in both years. The control was done by cross-checking specific interval data questions in both samples against each other and against the whole collection, by using standard reliability and randomness measures (t-test, covariance analysis). The null hypothesis was confirmed in all cases within the 0.001 level of significance.

The collection enables the computation of outcomes in at least two levels. Cross-sectional analyses proceed from taxonomies and comparisons of the whole sample regarded as a single, one time database. This usually aims at evaluating descriptors and relationships between variables of a quasistatic nature. Panel data analysis is also allowed if we take into account differences in selected items between the 1999 and the 2001 sub-samples, thereby describing trend patterns and evolving scenarios.

\section{Descriptors, taxonomies and efficiency within the traditional system}

The survey encompasses undergraduate students attending regular (degreed) courses contemporarily given at Resistencia (42.2\%), Corrientes $(50.17 \%)$ and Roque Saenz Peña campuses (7.65\%). 792 were residents in Resistencia, 611 in Corrientes, 131 in Roque Saenz Peña, 59 in Formosa and the rest in more than 130 locations of the region and neighboring countries. Throughout the academic year traditional, on campus, live classes are typically delivered in two 15-week semester periods. Although the class time loads vary across disciplines and units, most credit courses 
require instructor led lecture meetings at campus for a total between 90 to 135 hours in one semester (6 to 9 hours per week), excluding special commissions such as workshops, clinics and other extramural, compulsory activities. Full time undergraduates enrol in credit courses requiring class time loads of up to 30 hours a week as typical, thus not beyond 4-5 simultaneous units per semester. 927 individuals (35.3\%) said they had to change city of residence as a result of their studies, whereas $62.2 \%$ came from the same city where they attend courses (Figure 2).

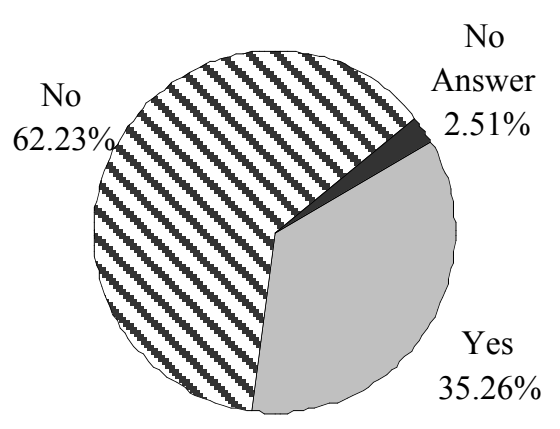

Figure 2: Change of residence as a result of studies

Additional monthly expenditures in housing and travel for $46.6 \%$ of the non-residents group were in the 200 to 400 Pesos range. 28\% within the non-residents group paid less than 200 Pesos and 14\% exceeded 400 Pesos per month. The average was 306.80 Pesos for individuals indicating their expenditure (the exchange rate in Argentina at the time of the survey (2001) was 1 US $\$=1$ Peso).

Course enrolment data (Figure 3) showed that $25.1 \%$ were enrolled in 4 simultaneous courses at the time of the survey, $24.3 \%$ in 3 courses, $15.2 \%$ in 2 courses, whilst the remainder were enrolled in 1, or 5 or more parallel courses in the survey semester. Almost half of the sample $(48.9 \%)$ had traditional, face to face lectures 5 days per week. Students with academic obligations spread out over 4 days comprised $19.1 \%$, people attending to scheduled classes 6 days per week comprised 11.1\%, and 3 days per week, $9.3 \%$. Only $6.4 \%$ said they had to commute to campus within a reduced, 1 or 2 day academic week.

$54.6 \%$ of respondents had completed up to 10 undergraduate units, generally equivalent to "freshmen" in the US educational system. There were $23.4 \%$ of individuals with more than 10 and up to 20 credit courses completed, generally equivalent to second years or "sophomores", whilst $10.7 \%$ had completed more than 20 units, generally equivalent to third or fourth years or "seniors". 


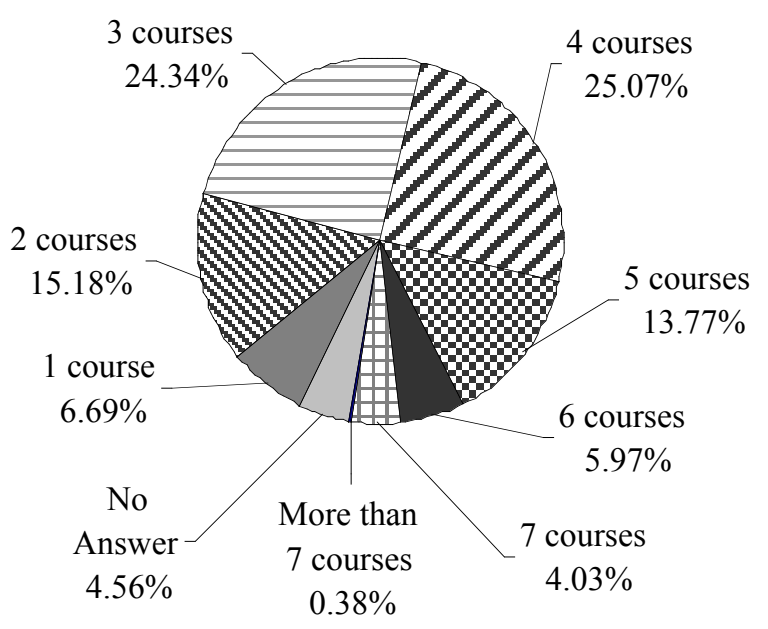

Figure 3: Enrolment in simultaneous credit courses

Regarding employment status, there were 749 full or part time workers $(28.5 \%)$, from which $42.5 \%$ reported some degree of clashing in their job and on campus class schedules: $19.6 \%$ with $20 \%$ to $50 \%$ overlapping time, another $19.2 \%$ being affected in less than $20 \%$; and $3.6 \%$ with schedule conflicts in over $50 \%$ of the classroom time. By comparing the working status of freshmen with sophomores and seniors, it becomes evident that employment is more common among the latter, at $32.3 \%$, compared with only $16.9 \%$ for first time registered students.

$11.1 \%$ of the students had exceeded non-attendance limits in current courses they were enrolled in, while $28 \%$ had plans to take examinations in at least one unit but just as free or independent learners, that is without attending the minimum of classes and/or lab assignments to qualify for ranking in the regular listing. When asked about time they actually can spend at on campus classes, $18.4 \%$ indicated 15 to 20 hours per week, whilst $16.2 \%$ indicated 10 to 15 hours, and $15.2 \%$ indicated 5 to 10 hours. Only $10.8 \%$ of respondents stated an attendance capability exceeding 25 hours per week. There were 833 students (31.7\%) who pointed out that they encountered at least one day per week on which they could not attend a scheduled class for one of their units. There were 510 individuals $(19.4 \%)$ who could not attend, even once per week. Analysing time spent in on campus classes showed that almost $72 \%$ attend at least one hour of classes per week. But among this big group, $24.1 \%$ said they actually cannot attend all the class time at campus they should, as required by their enrolment. 
Concerning the time spent in commuting to attend on campus classes, $63.7 \%$ travelled less than 1 hour per day, presumably people living and studying within the same city. Another $34.2 \%$ had to travel more than 1 hour per day. The distribution of the ratio of commuting time per week to on campus classroom time per week is depicted in Figure 4. In this distribution we can see a sort of efficiency ratio where the greatest part of respondents $(36.6 \%)$ spend between $30 \%$ and $60 \%$ of the time weekly devoted to on campus classroom sessions, in commuting to and from the campus. Another $29.3 \%$ needed $20 \%$ to $30 \%$, and $12.6 \%$ had to spend above $60 \%$ and up to $100 \%$ of their class time in travel. There is also a $10.7 \%$ group spending more time on travel than in the classroom (above $100 \%$ and up to $500 \%$ ).

Of course, this has also an impact on students' commuting and housing expenditures. We asked about two values: 1) Extra cost per day in commuting and miscellaneous (e.g. bus tickets, parking, etc) and 2) Extra cost per month in housing and meals (in the case of people who had to change city of residence during the academic year). Among those students attending on campus classes at least one day per week who reported on daily cost $(55.7 \%)$, the average is near 3 Pesos, but in the case of people living out of the city of their classes this is somewhat higher (3.80 Pesos). There are differences in daily cost averages for the three campuses surveyed, and also for schools and careers. Dentistry is the most expensive because of a higher daily cost in dental materials, and because dentistry students average 5.2 days attendance per week. The School of Law located in Corrientes is relatively cheap with 3.7 days per week at an average 2.49 Pesos per day, while the School of Engineering located in Resistencia also shows a low cost per day (1.65 Pesos), though engineering students averaged 4.3 days attendance per week.

Overall, the average cost in commuting and miscellaneous expenses, taking into account the average attending ratio for everybody (including those students without any spending) is 36.19 Pesos per month and the average total cost, including extra cost in housing and meals for those changing residence during the academic year, is almost 105 Pesos per month. With some further calculations we computed the average cost to the student per hour of on campus classes, 3.77 Pesos. This amount give us an indication towards assessing the economic feasibility of DL systems in this context.

\section{Learning environment and technology adoption factors}

We have considered computer and English proficiency, off campus PC access and off campus Internet access as integrating the technology adoption drivers and constraints for students in any DL project. Overall, 
we found $53.1 \%$ of individuals had off campus access to PCs and $36.8 \%$ had Internet access, with $17.5 \%$ using email regularly. By means of our panel analysis we found differences between the 1999 and the 2001 subsamples, mainly in the astounding growth of Internet access, from $15 \%$ to $57 \%$ ), and also in email usage, from $6.4 \%$ to $27.9 \%$ (Table 1).

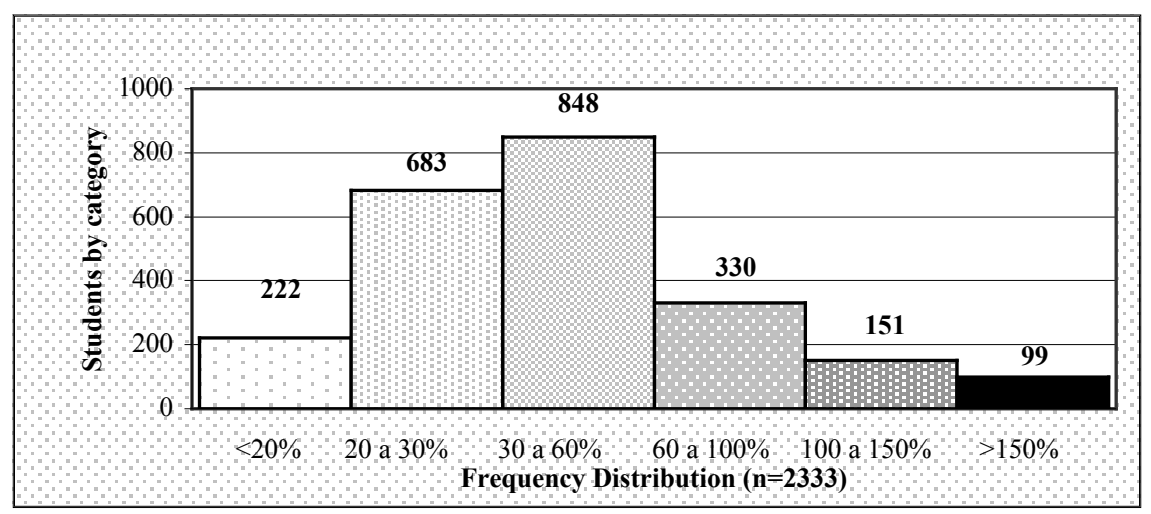

Figure 4: Time spent in commuting to campus / Effective on campus classroom time

Table 1: Off campus access to computers, Internet, email

\begin{tabular}{|l|c|c|c|}
\hline & $\begin{array}{c}1999 \text { Sub- } \\
\text { sample }\end{array}$ & $\begin{array}{c}2001 \text { Sub- } \\
\text { sample }\end{array}$ & $\begin{array}{c}\text { Total } \\
\text { sample }\end{array}$ \\
\hline Sample size (valid responses) & 1,268 & 1,361 & 2,629 \\
\hline $\begin{array}{l}\text { Individuals with off-campus PC } \\
\text { access }\end{array}$ & $\begin{array}{c}538 \\
(42.43 \%)\end{array}$ & $\begin{array}{c}859 \\
(63.12 \%)\end{array}$ & $\begin{array}{c}1,397 \\
(53.14 \%)\end{array}$ \\
\hline - at home & $57.25 \%$ & $42.96 \%$ & $48.46 \%$ \\
\hline $\begin{array}{l}\text { - at relatives or friends' } \\
\text { households }\end{array}$ & $25.65 \%$ & $15.48 \%$ & $19.40 \%$ \\
\hline $\begin{array}{l}\text { - cybercafes and public phone } \\
\text { centers }\end{array}$ & $0.37 \%$ & $15.83 \%$ & $9.87 \%$ \\
\hline $\begin{array}{l}\text { Individuals with off-campus } \\
\text { Internet access }\end{array}$ & 192 & 776 & 968 \\
\hline - at home & $56.77 \%$ & $16.57 \%$ & $(36.82 \%)$ \\
\hline $\begin{array}{l}\text { - at relatives or friends' } \\
\text { households }\end{array}$ & $0.52 \%$ & $47.02 \%)$ & $24.79 \%$ \\
\hline $\begin{array}{l}\text { - cybercafes and public phone } \\
\text { centers }\end{array}$ & 81 & $38.05 \%$ & $10.74 \%$ \\
\hline $\begin{array}{l}\text { Email access } \\
(6.38 \%)\end{array}$ & $(27.92 \%)$ & $(17.53 \%)$ \\
\hline
\end{tabular}


However, the place where students accessed PCs and the Internet has evidently shifted: in $1999,57.25 \%$ of PC users had it at home, compared with only $43 \%$ in 2001 . Another $25.65 \%$ in 1999 had PC access at a relative's or a friend's household, compared with $15.5 \%$ in 2001. Likewise, Internet access in 1999 was $56.8 \%$ at home for those students having access, but this was down to $16.9 \%$ in 2001 . Conversely, access via cybercafes and public phone centres grew substantially (0.5\% in 1999 to $47.7 \%$ in 2001). This may reflect the onset of Argentina's economic crisis and a decline in purchasing power for many people. It also reflects a mushrooming telecentre and cybercafe mania in urban areas with good access to broadband services, boosted by low tariffs and extended office hours.

Obviously, use of PCs and the Internet in Argentina and other developing countries depends on computer skills and English proficiency, as indicated in Figures 5 and 6. Insufficient knowledge ("Nothing" and "Scarce") in both skills affect respectively to $38 \%$ and $50 \%$. English proficiency appears to be more difficult to achieve, with just $14 \%$ of respondents assessing their personal foreign language skills as "very good" or "good", this value comparing with computer literacy where $30.3 \%$ of them assess themselves as "very good" or "good".

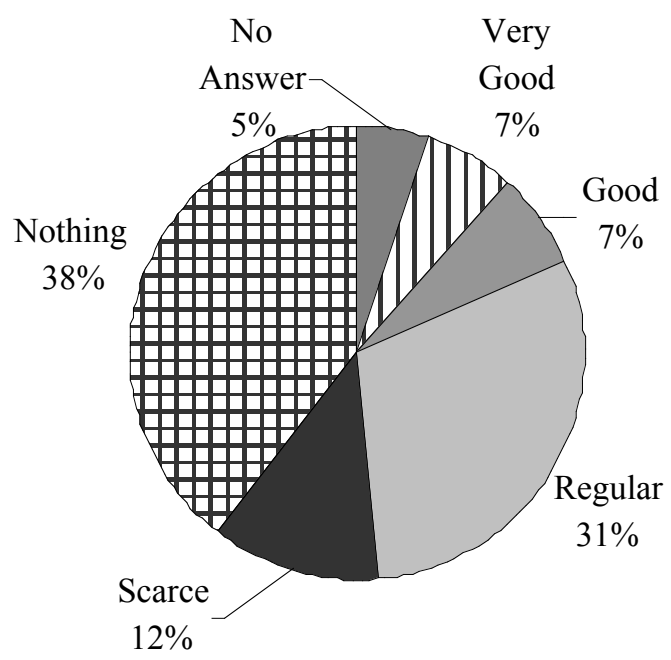

Figure 5: English working knowledge self assessment

Another aspect concern to students' perception on the distribution of classroom/campuses and the schedule of live classes at campus, where we used a 5-point Likert scale (from 1. "Totally appropriate" to 5. "Totally inappropriate"). Even when the majority assessed both aspects as 2 ("fairly 
appropriate"), there is more consensus on the suitability of class scheduling under this category $(44.3 \%)$ than respect to classroom/ campus allocation $(35.1 \%)$. We can deduct from this that prospective class schedules in the case of adopting any synchronous learning system would not require so many changes. On the other hand, it might be also indicating the perception of fewer opportunities to make schedule changes in the current distribution of live classes at campus (Figure 7).

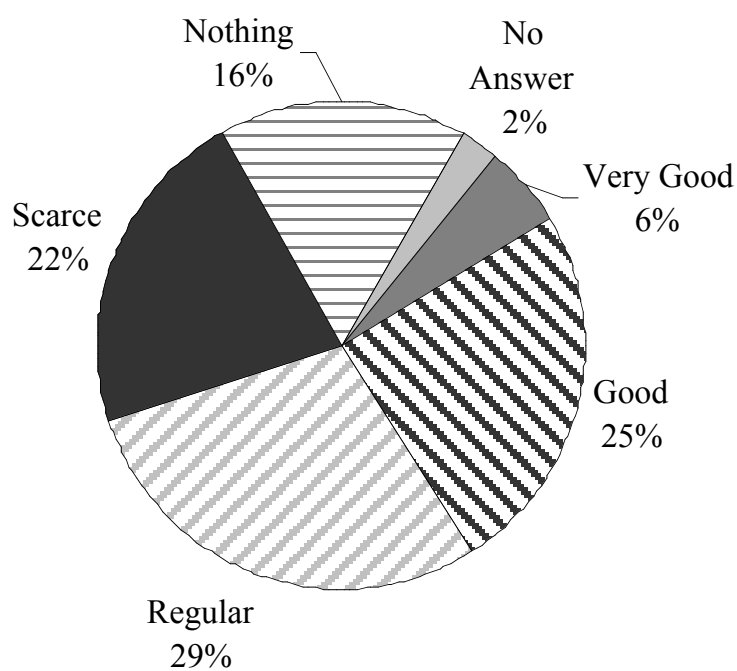

Figure 6: PC working knowledge self assessment

\section{Student expectations and preferences about distance learning alternatives}

A measurement of preferences about the best (or rather, the most suitable) option for implementing distance learning was obtained using a 5-point Likert scale (1. "Very important" to 5 . Not that important), and therefore we computed the responses in two categories, "Very Important" and "Weighted total" (Figure 8). We asked students about six hypothetical options:

A. Synchronous 2-way full duplex transmission of live classes to other UNNE campuses in remote locations.

B. Idem, idem to virtual classrooms in locations so far without UNNE campuses (elsewhere).

C. Recording and retransmission of lectures in alternative schedule slots, within the same campus location 
D. Email consultation with lecturers and professors in specific schedule slots.

E. Discussion weblist, accessible only by subject and course registered students in specific schedule slots.

F. Others (specify)

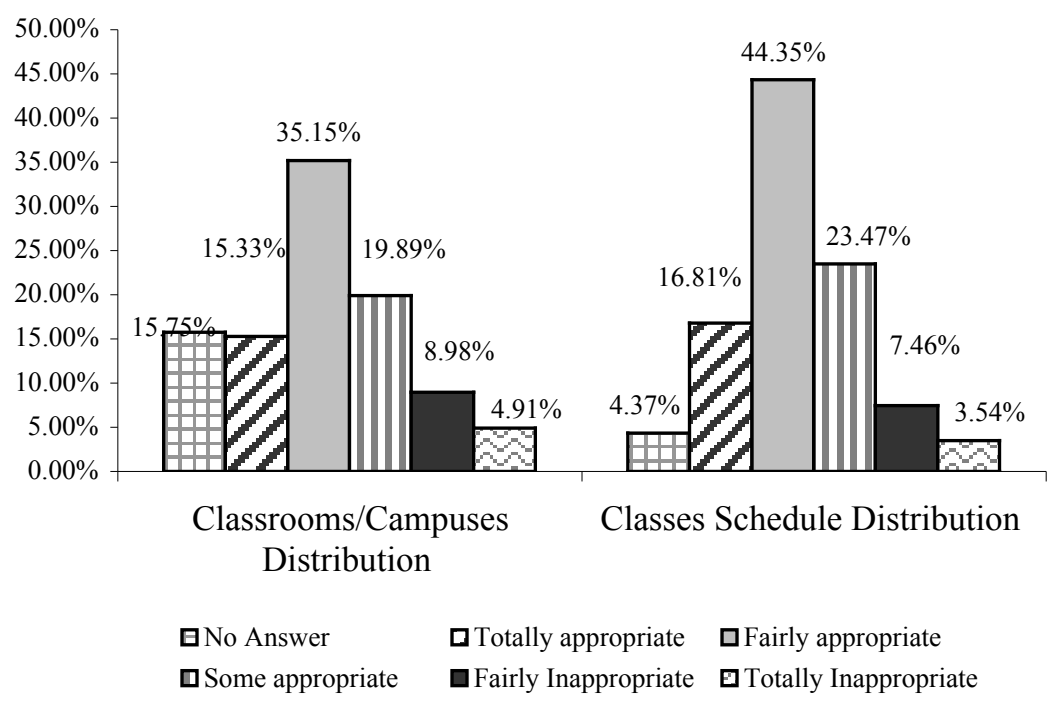

Figure 7: Subjective assessment of actual classroom/ campuses location (a) and classes schedule (b)

We found an almost even distribution of the preferences, and none of them as notably prevalent in both the weighted average and just the "Very important" hits. However, in the next question students gave their opinion about the most suitable technology access option for students whose permanent residence is not in the city where live classes for their courses are conducted. Students were given three response options, as follows.

a. Concentrated virtual campus: This option entails live, 2-way full duplex Intranet video and audio transmission to virtual classrooms in remote locations according to specific schedule slots (arranged and operated by UNNE, thus free of charge for registered students on a collective access basis).

b. Scattered virtual campus: Individual access via home PC and Internet, anywhere, with remote connection to ISPs and charges paid by the student.

c. Other options (specify) 
Option a. reached almost $60 \%$ of OK responses, option b. near $23 \%$, option c. $4.6 \%$ (the main other option specified was "both a. and b."), and there were near $13 \%$ no responses (Figure 9).

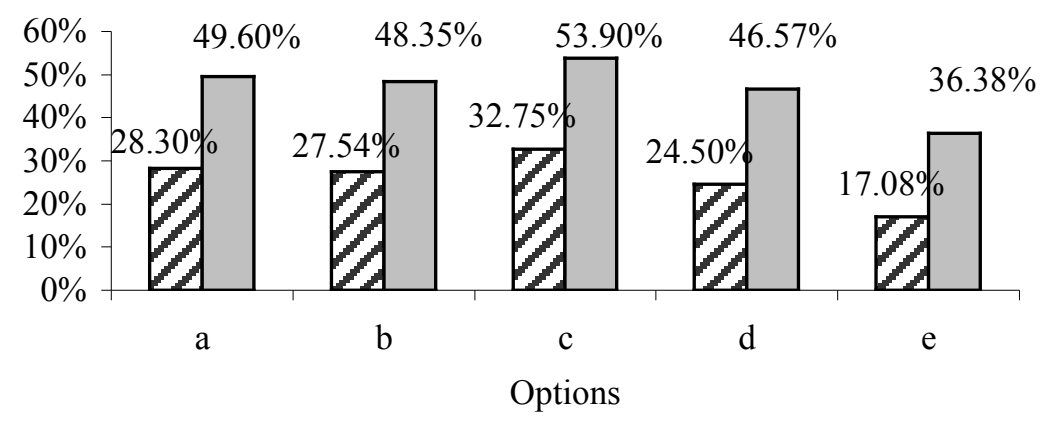

$\square$ Very Important

Weighted Total

Figure 8: Pre-adoption perception about alternatives for distance learning implementation

As another conditioning factor, we asked students about their foreseeable motivation and concentration to take classes via distance learning, on account that DL, in the lack of teachers' physical, face to face contact and its associated interaction level, requires more in both. Again, we used a 5point Likert scale so as to let students assess themselves regarding this hypothetical situation. Almost $60 \%$ considered it as "Normal", another $14 \%$ as "High", $14.7 \%$ as "Fair", and 3.7\% as "Low".

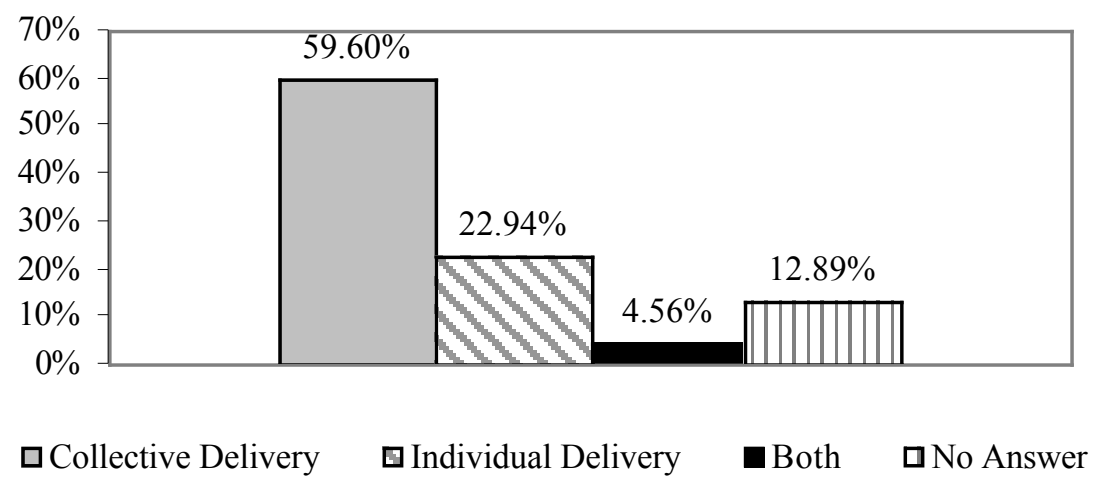

Figure 9: Pre-adoption perception about preferences for distance learning access 
Finally, there was a question about the optimal proportions of face to face classes and virtual classes delivered remotely, if implementing a synchronous DL system within UNNE (options A and B as described above). The great majority preferred a "50-50" share, with class time loads up to 10 hours a week for each delivery form (50.2\% for live classes and $53.9 \%$ for virtual, synchronous 2-way full duplex DL classes).

\section{Conclusion}

In this case study, the assessment of perceptions of students has confirmed our previous surmises in relation to conditions such as working profile, attendance at classes, and limitations in PC and Internet access, along with new information about computer and English skills, commuting time and cost per day per live classroom hour. The survey has provided a good statistical background to further develop a serious DL initiative. For reasons of space we have described here just the main taxonomies, but the richness of the data arises from the possibility of cross-comparisons by career, location and student profile.

By considering data on time actually spent in on campus lectures, the number of simultaneous courses undertaken, number of days and time spent in commuting to campus, timetable clashes for workers and so on, we can estimate the size of the effort required from students under the traditional system, in terms of time and costs. Two assessments, one for residents in a different city, and another for non-native residents (individuals who had to move as a result of studies), enable estimates of requirements and feasibility for DL projects with respect to actual student groups. Example: an average, raw cost of 3.77 Pesos per hour of on campus classes within the traditional system yields an upper bound vis-àvis an equivalent, hypothetical synchronous DL lecture over inter-campus optical networks, including capital and operating expenditures.

Furthermore, there are indications to target potential DL benefited groups, eg. among those $35.26 \%$ of non-residents who had to change to change city of residence (Figure 2) and likely, among that $23.2 \%$ spending over $60 \%$ of their effective on campus class time in daily commuting from other cities (Figure 4). Obviously, further adjustments to these raw indications must bear sense of cost differences between campus locations, careers, school regimes. It has to be realistically added the opposite effects of: 1) hidden or marginal demand, eg. prospective non-native residents - not yet decided to change residence as a result of career choices, and 2) effective adoption and usage rates for an hypothetical new system constrained by actual attitudinal profiles, type of class / discipline taught, quality / availability of technology choices and other conditioning factors which, in spite of efficiency can ultimately favour physical commuting over DL. Finally, 
alternative project scenarios should include the combined impact on enrolment rates of student population growth in future years, along with the creation of virtual campuses in new, prospective locations.

However, the most important findings are those elements suitable to map relative deficits, strengths and particular needs from the pedagogical design point of view. Comparing the 1991 and the 2001 sub-samples, there is a clear trend towards PC and Internet access from public sites (libraries, cybercafes, etc), at the expense of access at home, friends or relatives. This is consistent with the preference for collective versus individual delivery of DL classes (concentrated versus scattered virtual campus, Figure 8). English as a foreign language still remains an obstacle for many, while PC proficiency seems to have improved steadily from 1999 to 2001: does this constitute a key design clue for content and instructional design, in the event of implementation of synchronous DL? The latest empirical research on course websites, for example, apparently confirms that perceived usefulness and perceived ease of use are key determinants on their acceptance, according to David's 1986 technology acceptance theory (Selim, 2003).

We recognise the difficulties and limitations of pre-adoption perception studies, where some of the questions require the respondent to guess what a virtual class would be like, whether he or she would be comfortable or uncomfortable taking it, and whether he or she might obtain any net advantage when attending distance learning classes. The assessment of variables of the Stubbs \& Burnham model (Time and place independence, Available communication paths, Level of realism, Ease of use and Immediacy) and those in David's technology acceptance theory is not possible without tangible experience by both students and teachers.

However, there is also a parallel need for cost conscious and effort conscious strategies in the introduction of technology in the educational system, as long as educators cannot run as fast as engineers, and pedagogical projects take time to implement. Indeed, even today "many programs are still run on opinion and perception rather than fact." The evaluation instruments are "consensus of reflected opinion and perception rather than fact" (Lane, 1989). Synchronous transmission of live classes via optical broadband networks is not at all a new idea; rather its adoption is driven by conditioning pedagogical and social contexts (Murakami, 1983).

\section{References}

Burnham, B. R. \& Walden, B. (1997). Interactions in distance education: A report from the other side. In T. Mulder \& T. C. Reeves (Eds), Educational Multimedia/Hypermedia and Telecommunications. Association for the Advancement of Computing in Education (AACE). Charlottesville, VA. 
Davis, F. D. (1986). A Technology Acceptance Model for Empirically Testing New EndUser Information Systems: Theory and Results. Doctoral dissertation, Sloan School of Management, Massachusetts Institute of Technology. Cambridge, MA.

Davis, F. D. (1989). Perceived usefulness, perceived ease of use and user acceptance of information technology. MIS Quarterly, 13(2), 319-339.

Davis, F. D. (1993). User acceptance of information technology: System characteristics, user perceptions and behavioral impacts. International Journal of Man-Machine Studies, 38, 475-487.

Goussal, D. M. \& Udrízar Lezcano, M. S. (2001). Muestreo preliminar de claustro estudiantil para condiciones de implantación de sistemas de educación a distancia y campus virtuales en la Universidad Nacional del Nordeste. (II Alternativas) Actas, R. de Comunicaciones Científicas y Técnicas-UNNE. Corrientes, Argentina.

Goussal, D. M. \& Udrízar Lezcano, M. S. (2001). Muestreo preliminar de claustro estudiantil para condiciones de implantación de sistemas de educación a distancia y campus virtuales en la Universidad Nacional del Nordeste. (I Taxonomía) Actas, R. de Comunicaciones Científicas y Técnicas -UNNE. Corrientes.

Goussal, D. M. \& Udrízar Lezcano, M. S. (2000). Evaluación muestral de claustro docente para condiciones de implantación de tecnologías de educación a distancia y campus virtuales con interconexión sincrónica de banda ancha. Actas, R. de Comunicaciones Científicas y Técnicas -UNNE. Resistencia, Argentina.

Goussal, D. M. \& Udrízar Lezcano, M. S. (2000). Broadband networks in rural areas: Engineering options and policy implications of the bandwidth flooding criterion. Proceedings 22nd Annual Pacific Telecommunications Conference (PTC 2000). Honolulu, USA.

Goussal, D. M. \& Udrízar Lezcano, M. S. (1997). Análisis de opciones de implantación de una ruta óptica transversal para interconexión multimedia de campus virtuales. Actas, $R$. de Comunicaciones Científicas y Técnicas - SECYTUNNE Vol.4 Corrientes, Argentina: 8105-8108.

Johnstone, S. (2000). Making sense of today's US higher education market: The national trends. Proceedings 22nd Annual Pacific Telecommunications Conference (PTC2000). Honolulu, USA.

Karahanna, E. (1993). Evaluative Criteria and User Acceptance of End User Information Technology: A Study of End-user Cognitive and Normative Pre-Adoption Beliefs (Innovation Diffusion). PhD Dissertation, University of Minnesota, USA.

Karahanna, E., Straub, D. W. \& Chervany, N. L. (1999). Information technology adoption across time: A cross-sectional comparison of pre-adoption and postadoption beliefs. MIS Quarterly, 23(2), 183-213.

Lane, C. (1989). A selection model and pre-adoption evaluation instrument for video programs. American Journal of Distance Education, 3(3), 46-57.

Marney-Petix, V. C. (1996) Hybrid sync/ async distance learning options at the University of Santa Cruz Extension and Marpet University. Proceedings 18th Annual Pacific Telecommunications Conference (PTC96), Vol II. Honolulu, USA.

Mann, D. (1999). Documenting the effects of instructional technology: A fly-over of policy questions. The Secretary's Conference on Educational Technology 1999. Washington DC, USA. [verified 10 Oct 2003] http:/ / www.ed.gov/rschstat/eval/tech/techconf99/whitepapers/paper6.html 
Moore, G. C. and Benbasat, I. (1991). Development of an instrument to measure the perceptions of adopting an information technology innovation. Information Systems Research, 2(3), 192-222.

Murakami, R. (1983). Application of optical fiber communication system. (Conference) II Congreso y Exposición Internacional "Telecomunicaciones 83"Año Mundial de las Comunicaciones. Buenos Aires, Argentina.

O`Malley, J. (1999). Students perceptions of distance learning, online learning and the traditional classroom. Online Journal of Distance Learning Administration, 2(4). State University of West Georgia.[verified 10 Oct 2003] http: / / www.westga.edu/ distance/ omalley24.html

Redding, G. (2000). Advanced distributed learning: Building the DoD learning environment of the future. Proceedings 22nd Annual Pacific Telecommunications Conference (PTC2000). Honolulu, USA.

Renner, J. (1995). Convergence of communications technologies to achieve educational excellence. A case for the virtual campus. Proceedings 17th Annual Pacific Telecommunications Conference (PTC-95). Honolulu, USA.

Selim, H. M. (2003). An empirical investigation of student acceptance of course websites. Computers E Education, 40, 343-360.

Shakeshaft, C.(1999). Measurement issues with instructional and home learning technologies. Secretary's Conference on Educational Technology 1999. Washington DC, USA. [verified 10 Oct 2003] http:/ / www.ed.gov/rschstat/eval/tech/techconf99/whitepapers/paper9.html

Stubbs, S. \& Burnham, B. (1990). An instrument for evaluating the potential effectiveness of electronic distance education systems. American Journal of Distance Education, 4(3).

Trushell, J., Reymond, C., Herrera, R. \& Dixon, P. (1997). Undergraduate students' use of information communicated during email "tutorials". Computers $\mathcal{E}$ Education, 28(1), 11-21.

Walters, R. \& Reed, N. (1997). Outcome analysis of distance learning: A comparison between conventional and independent study instruction. Dept of Computer Science, University of California Davis, USA. [verified 10 Oct 2003] http: / / horizon.unc.edu/projects/monograph/CD/Science_Mathematics/Walters.asp

Darío M. Goussal and María Sandra Udrízar Lezcano Grupo de Investigación en Telecomunicaciones Rurales Universidad Nacional del Nordeste - Resistencia, Argentina Rural Telecommunications Research Group - Northeastern University at Resistencia, Argentina http://ing.unne.edu.ar/gtr.htm 